\title{
Lateral insertion is a good prognostic factor after in situ fixation in slipped capital femoral epiphysis
}

Shigeo Hagiwara ${ }^{1 \dagger}$, Junichi Nakamura ${ }^{1 *}{ }^{+}$, Makoto Kamegaya $^{2}$, Takashi Saisu ${ }^{3}$, Jun Kakizaki ${ }^{3}$, Seiji Ohtori ${ }^{1}$, Shunji Kishida ${ }^{1}$ and Kazuhisa Takahashi ${ }^{1}$

\begin{abstract}
Background: In situ fixation (ISF) is standard treatment for slipped capital femoral epiphysis (SCFE) to stabilize the epiphysis and to prevent further slip. The aim of this study was to clarify the incidence of slip progression after ISF and its prognostic factors.

Methods: We retrospectively reviewed 53 hips in 49 consecutive SCFE patients who underwent single screw ISF and were followed until physeal closure. Clinical and radiographic findings were viewed to assess progression of the posterior tilting angle (PTA).

Results: Mean PTA was 33.4 degrees (range, 18 to 75 degrees) at ISF and 35.9 degrees (range, 18 to 75 degrees) at physeal closure with progression of PTA of 2.5 degrees (range, -2 to 19 degrees). Slip progression occurred in 28 of 53 hips (53\%), and more than five degrees of progression occurred in 14 hips (26\%). Multiple regression analysis revealed that point of screw insertion (one point for lateral and two points for medial) was a significant prognostic factor for progression of the slip by the following formula: (progression of PTA) $=-1.523+2.701 \times($ point of screw insertion), $R^{2}=0.148, p=0.005$.
\end{abstract}

Conclusions: The current study showed that a screw inserted from the lateral side to the intertrochanteric line prevented postoperative slip progression.

\section{Background}

Slipped capital femoral epiphysis (SCFE) is the most frequent hip problem in adolescents [1-4]. Mechanical stress from body weight is thought to be responsible for progression of posterior slip of the epiphysis, leading to groin pain and external rotation of the lower extremity [5]. Morphology of the proximal femur has been shown to associate with the femoro-acetabular impingement in adolescents and young adults [6-8], resulting in osteoarthritis of the hip [9-11]. Therefore, early diagnosis and optimal treatment is crucial to improve the outcome.

Sometimes osteotomy is needed to realign the proximal femur [12]. In situ fixation (ISF) of SCFE is widely accepted as an initial treatment to stabilize the capital

\footnotetext{
* Correspondence: njonedr@chiba-u.jp

${ }^{\dagger}$ Equal contributors

'Department of Orthopaedic Surgery, Graduate School of Medicine, Chiba University, 1-8-1 Inohana, Chuo-ku, Chiba City, Chiba 260-8677, Japan
} Full list of author information is available at the end of the article epiphysis and to prevent further slip [13-15]. However, slip progression can occur even after ISF and several osteotomy procedures for realignment of the proximal femur have been proposed [12]. The aim of this study was to clarify the incidence of slip progression after ISF, and to identify the prognostic factors that can predict slip in SCFE patients.

\section{Methods}

The study protocol was approved by the institutional review board (Research Ethics Committees, Chiba Children and Adult Orthopaedic Clinic) and all the patients gave written informed consent. This retrospective observational cohort study included only SCFE patients who underwent single screw ISF as the initial treatment from 1996 to 2010 and were followed until physeal closure. Patients with avascular necrosis, endocrine disorders, multiple screw fixation, and preventive fixation for asymptomatic contralateral hip were excluded. Joint- based analysis was applied 
in this study. The patients were admitted to the hospital and kept in bed with one $\mathrm{kg}$ of positional traction until the operation.

The Lauenstein method was applied for the lateral image as follows: care was always taken to keep the patient's trunk in a semilateral decubitus position, 45 degrees leaning to the affected side and keeping the patient's thigh on the platform with 90 degrees hip flexion. posterior tilting angle (PTA) was measured by neck-shaft angle using the Southwick procedure [16]. ISF was basically indicated when PTA was 40 degrees or less. In cases of PTA more than 40 degrees, ISF could be indicated only if the femoral head was round on the anterior-posterior X-ray image and the range of motion was well maintained over 90 degrees of flexion. Each patient was carefully laid on the operating table without traction under general anesthesia. Attention was paid throughout the operation not to reduce the slipped femoral epiphysis by traction or internal rotation and not to penetrate a guide wire into the hip joint space without exiting the femoral neck and re-entering the femoral head, damaging the posterior vascular structures, as viewed under the image intensifier. Then, a Richard titan cannulated screw with $16 \mathrm{~mm}$ thread (6 threads) and $6.5 \mathrm{~mm}$ diameter (Smith\&nephew, Memphis) was inserted. ISF was performed by multiple surgeons under a single supervisor. Postoperatively, patients were restricted to non-weight bearing for three to six weeks using a wheel chair or crutches depending on the stability. Then, full weight bearing was permitted at six weeks in chronic SCFE, and at three months in both acute and acute on chronic types of SCFE. PTA was continuously measured from before ISF to physical closure.

\section{Statistical analysis}

Radiological evaluation of PTA included the screw position $[16,17]$, the distribution of threads across the epiphysis [18], and the point of screw insertion [19]. Slip progression was defined as a change of more than five degrees of PTA based on Rao et al. [20]. The screw position was determined using the Aronson and Carlson system [17]: 1 point, the central axis of the screw is located over the center line of the femoral head or within a distance equal to one-half the diameter of the screw; 2 points, the distance between the axis of the screw and center line of the femoral head is between one-half and one screw-diameter; and 3 points, the axis of the screw is located more than one screw-diameter from the center line of the femoral head. The distribution of threads across the epiphysis was determined using the method of Upasani [18]: 1 point, $40-60 \%$ of the threads engage the physis; 2 points, $<40 \%$ or $>60 \%$ of the threads engage the physis. The point of screw insertion was defined as follows: 1 point, lateral to the intertrochanteric line both in anteroposterior and lateral views (Figure 1); and 2 points, medial to the intertrochanteric line (Figures 2 and 3). Goodwin's classification [19] of screw head positioning was modified by the exact screw insertion. The radiographic evaluations were independently performed by two authors; however, the first author's decision was adopted regarding other parameters. Cohen's quadratic weighted kappa statistic [21] was used to assess the inter-observer and intra-observer reliabilities of the evaluation regarding the screw position, the point of screw insertion, and the distribution of threads. Intra-class correlation coefficients (ICC) were used to assess the inter-observer and intra-observer reliabilities of the evaluation of PTA. Step-wise multiple regression analysis was performed to determine the prognostic factors for slip progression after ISF. Candidate factors were the age at ISF, body mass index (BMI), onset pattern (1 point in chronic, 2 points in acute on chronic, and 3 points in acute), grade of stability ( 1 point in stable and 2 points in unstable), PTA at ISF, the screw position, distribution of threads across the epiphysis, and the point of screw insertion. A probability value $<0.05$ was considered to be significant with SPSS 16.0 J (SPSS Inc., Chicago, IL).

\section{Results}

We registered 112 consecutive hips in 98 SCFE patients (75 boys and 23 girls) from 1996 to 2010. Initially, ISF was performed on 77 hips in 64 SCFE patients. Subsequently, we excluded four hips in four patients with avascular necrosis, six hips in three patients with endocrine disorders, six hips in six patients with double screw fixation, and six hips with preventive fixation for asymptomatic contralateral hip. Of the remaining 55 hips, 53 hips (24 right, 21 left, and 4 bilateral) in 49 patients (40 boys and 9 girls) were observed until physeal closure with a $96 \%$ follow-up rate. The mean time to physeal closure, i.e. follow-up period, was 12.9 months (range, 3 to 30 months).

Mean age at ISF was 11.8 years (range, 8 to 14 years) and mean BMI was 24.7 (range, 14.6 to 36.2). Mean duration from first visit to our hospital to ISF was 9.5 days (range, 1 to 52 days). Onset of symptoms was acute in 12 hips, acute on chronic in 12, and chronic in 29. Functionally, 48 hips were stable and 5 were unstable.

Cohen's quadratic weighted kappa for inter-observer reliability was 0.700 for the screw position, 0.886 for the point of screw insertion, and 0.798 for the distribution of threads. ICC was 0.977 in PTA. Cohen's quadratic weighted kappa for intra-observer reliability was 0.938 for the screw position, 0.876 for the point of screw insertion, and 0.588 for the distribution of threads. ICC was 0.989 in PTA.

Mean PTA at ISF was 33.4 degrees (range, 18 to 75 degrees). Mean PTA at physeal closure was 35.9 degrees (range, 18 to 75 degrees) with progression of PTA of 2.5 degrees (range, -2 to 19 degrees). We performed an 

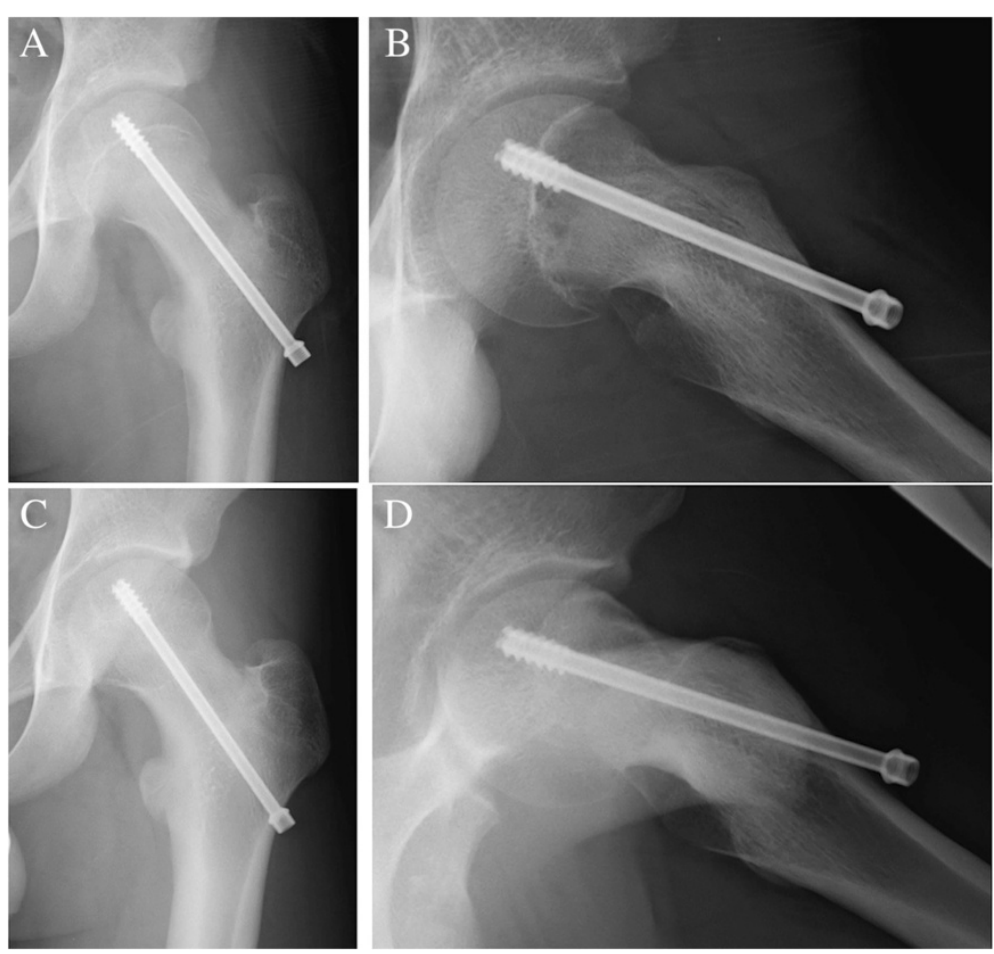

Figure 1 Radiographs of the left hip in a 13-year-old boy with SCFE. Anteroposterior (A) and lateral (B) radiographs immediately after in-situ fixation (ISF) for acute on chronic and stable type hips at 42 degrees of posterior tilting angle (PTA). A single screw was inserted from the lateral point. Anteroposterior (C) and lateral (D) radiographs at physeal closure. PTA was maintained without progression of the slip.
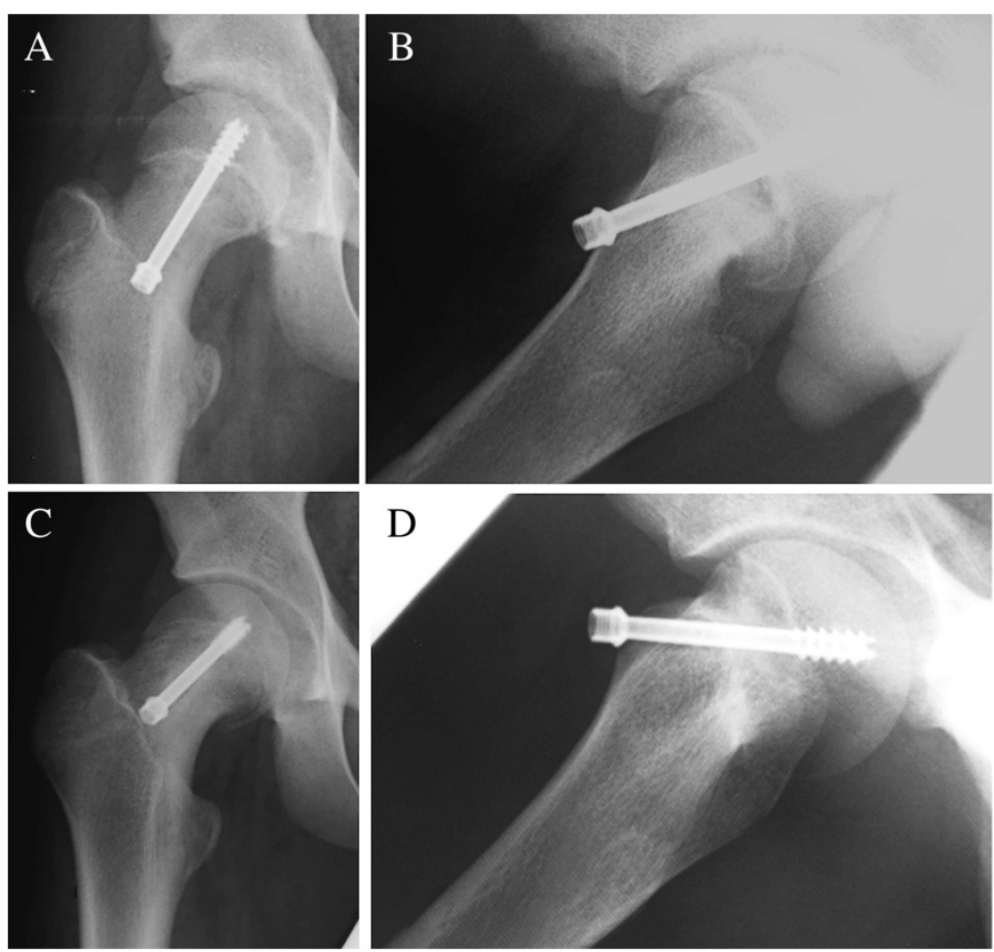

Figure 2 Radiographs of the right hip in a 14-year-old boy with SCFE. Anteroposterior (A) and lateral (B) radiographs immediately after ISF for chronic and stable type hips at 38 degrees of PTA. A single screw was inserted from the medial point to the center of the epiphysis perpendicularly. Anteroposterior (C) and lateral (D) radiographs at physeal closure. Slippage of the epiphysis had progressed to 43 degrees of PTA 17 months after surgery. 

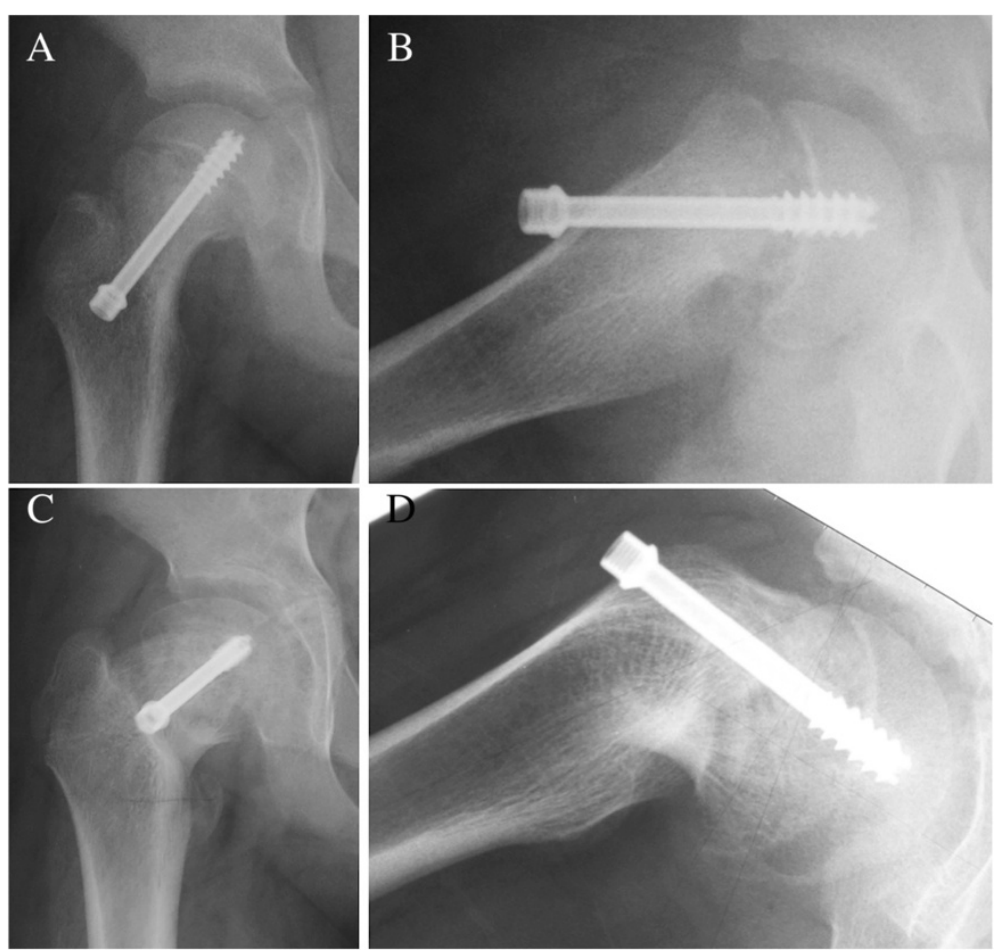

Figure 3 Radiographs of the right hip in a 10-year-old boy with SCFE. Anteroposterior (A) and lateral (B) radiographs immediately after ISF for chronic and stable type hips at 37 degrees of PTA. A single screw was inserted from the medial point to the center of the epiphysis perpendicularly. Anteroposterior (C) and lateral (D) radiographs at physeal closure. PTA had progressed to 56 degrees 18 months after surgery due to excessive retroversion of the femoral neck.

additional osteotomy after physeal closure in four hips in which PTA was more than 45 degrees and range of motion was restricted with the Drehmann sign [12]. There were no screw penetrations into the joint space and or fractures around the screws. Screw position was center in 29 hips, next to center in 19 hips, and apart from center in five hips. The distribution of threads across the epiphysis was between 40 and $60 \%$ in 33 of 53 hips. The point of insertion was lateral in 30 hips and medial in 23 hips.

Slip progression occurred in 28 of 53 hips (53\%), and more than five degrees of progression occurred in 14 hips (26\%). Table 1 shows comparison of slip-retention group (five degrees or less) and slip-progression group (more than five degrees). Both PTA at ISF and at physeal closure were not significantly different between the slipretention group and the slip-progression group. Progression of PTA was naturally significantly larger in the slipprogression group than in the slip-retention group (6.9 degrees versus 0.9 degrees, $p=0.001$ ). Rate of lateral insertion was significantly higher in the slip-retention group than in the slip-progression group $(p=0.011)$. Acute on chronic type of SCFE was more in the slipretention group than in the slip-progression group with a statistical difference $(p=0.043)$. Furthermore, Table 2 shows comparison of the lateral insertion group and the medial insertion group. PTA at ISF was significantly larger in the medial group than in the lateral group (37.7 degrees versus 29.6 degrees, $p=0.004$ ). PTA at physeal closure was also significantly larger in the medial group than in the lateral group (41.6 degrees versus 30.8 degrees, $p=0.001$ ). Consequently, progression of PTA was 3.9 degrees for the medial group and 1.2 degrees for the lateral group with a statistical difference $(p=0.001$, Figure 4).

Multiple regression analysis revealed that point of screw insertion (one for lateral and two for medial) was an independent prognostic factors for slip progression, and could be predicted by the following formula: (progression of PTA $)=($ progression of PTA $)=-1.523+2.701 \times$ (point of screw insertion), $\mathrm{R}^{2}=0.148, p=0.005$.

\section{Discussion}

A lateral point of screw insertion was an independent prognostic factor for slip progression after ISF in SCFE patients. The current study showed that a single screw inserted from lateral to intertrochanteric line prevented postoperative slip progression without the risk of screw penetration into the joint. One of the reasons may be because the thickness of the cortical bone at the proximal femoral metaphysis increases from the medial to the lateral aspect and the screw can go through a longer 
Table 1 Comparison of slip-retention group and slip-progression group

\begin{tabular}{|c|c|c|c|}
\hline & $\begin{array}{l}\text { Retention } \\
\text { group (39 hips) }\end{array}$ & $\begin{array}{l}\text { Progression } \\
\text { group (14 hips) }\end{array}$ & $p$ value \\
\hline Age (years) & 11.9 & 11.6 & $0.420^{*}$ \\
\hline BMI & 24.2 & 26.1 & $0.118^{*}$ \\
\hline PTA at ISF (degrees) & 33.7 & 32.6 & $0.944^{*}$ \\
\hline $\begin{array}{l}\text { PTA at physeal } \\
\text { closure (degrees) }\end{array}$ & 34.6 & 39.5 & $0.077^{*}$ \\
\hline $\begin{array}{l}\text { Progression of } \\
\text { PTA (degrees) }\end{array}$ & 0.9 & 6.9 & $0.001^{*}$ \\
\hline $\begin{array}{l}\text { SCFE type (acute: acute } \\
\text { on chronic: chronic) }\end{array}$ & 9:12:18 & 3:0:11 & 0.0439 \\
\hline $\begin{array}{c}\text { Stability (stable: } \\
\text { unstable) }\end{array}$ & $35: 4$ & $13: 1$ & $1.000 \S$ \\
\hline Screw position (1:2:3)† & $22: 14: 3$ & $7: 5: 2$ & 0.7599 \\
\hline $\begin{array}{c}\text { Distribution of threads } \\
(1: 2) \neq\end{array}$ & $17: 22$ & $3: 11$ & $0.203 \S$ \\
\hline $\begin{array}{l}\text { Point of insertion } \\
\text { (lateral:medial) }\end{array}$ & $25: 14$ & $3: 11$ & $0.011 \S$ \\
\hline $\begin{array}{l}\text { Time for full-weight } \\
\text { bearing (weeks) }\end{array}$ & 4.8 & 3.4 & $0.165^{*}$ \\
\hline $\begin{array}{l}\text { Time for physeal } \\
\text { closure (months) }\end{array}$ & 12.1 & 15.4 & $0.088^{*}$ \\
\hline
\end{tabular}

Slip-retention group means five degrees or less of PTA increase and slip-progression group means more than five degrees. $\dagger 1$ point, the central axis of the screw is located over the center line of the femoral head or within a distance equal to one-half the diameter of the screw; 2 points, the distance between the axis of the screw and center line of the femoral head is between one-half and one screw-diameter; and 3 points, the axis of the screw is located more than one screw-diameter from the center line of the femoral head. $\neq 1$ point, $40-60 \%$ of the threads engage the physis; 2 points, $<40 \%$ or $>60 \%$ of the threads engage the physis. *Mann-Whitney's $U$ test, $\cap$ Pearson's $X^{2}$ test, §Fisher's exact probability test.

distance in the metaphysis, resulting in secure stability of the screw (Figure 1). Goodwin et al. suggested that a screw inserted from medial to the intertrochanteric line perpendicular to the physis caused acetabular impingement on the anterior acetabular rim and the screw head in moderate to severe SCFE patients [19]. Goodwin's classification based on screw head positioning [19] was modified in the current study to the exact screw insertion using anteroposterior and lateral radiographs. The screw head positioning was determined by the length of the screw as well as the exact screw insertion. Thus, we regarded the point of insertion itself as more reliable. Another advantage of lateral insertion is that it is easy to remove the screw at the time of additional osteotomy by a single incision in severe SCFE. We recommend that lateral insertion technique is effective for ISF in SCFE patients.

However, best practices for ISF have been controversial [22-25]. Several studies have advocated medial insertion of the screw to penetrate the physis perpendicular at the center of the epiphysis $[17,26,27]$. Aronson et al. recommended that the screw should be inserted from
Table 2 Comparison of lateral insertion group and medial insertion group

\begin{tabular}{|c|c|c|c|}
\hline & $\begin{array}{l}\text { Lateral group } \\
\text { (28 hips) }\end{array}$ & $\begin{array}{l}\text { Medial group } \\
\text { (25 hips) }\end{array}$ & $p$ value \\
\hline Age (years) & 12.0 & 11.7 & $0.274^{*}$ \\
\hline $\mathrm{BMI}$ & 23.9 & 25.6 & $0.113^{*}$ \\
\hline PTA at ISF (degrees) & 29.6 & 37.7 & $0.004^{*}$ \\
\hline $\begin{array}{c}\text { PTA at physeal closure } \\
\text { (degrees) }\end{array}$ & 30.8 & 41.6 & $0.001^{*}$ \\
\hline Progression of PTA (degrees) & 1.2 & 3.9 & $0.001^{*}$ \\
\hline $\begin{array}{l}\text { Ouctome (slip retention: } \\
\text { slip progression) }\end{array}$ & $25: 3$ & 14:11 & $0.011 \S$ \\
\hline $\begin{array}{l}\text { SCFE type (acute: acute } \\
\text { on chronic: chronic) }\end{array}$ & 8:9:11 & $4: 3: 18$ & 0.053 \\
\hline Stability (stable: unstable) & $25: 3$ & $23: 2$ & $1.000 \S$ \\
\hline Screw position $(1: 2: 3) \dagger$ & 19:6:3 & $10: 13: 2$ & 0.0679 \\
\hline Distribution of threads $(1: 2) \neq$ & $12: 16$ & $8: 17$ & $0.571 \S$ \\
\hline $\begin{array}{l}\text { Time for full-weight } \\
\text { bearing (weeks) }\end{array}$ & 4.0 & 4.9 & $0.378^{*}$ \\
\hline $\begin{array}{l}\text { Time for physeal } \\
\text { closure (months) }\end{array}$ & 13.5 & 12.4 & $0.513^{*}$ \\
\hline
\end{tabular}

+1 point, the central axis of the screw is located over the center line of the femoral head or within a distance equal to one-half the diameter of the screw; 2 points, the distance between the axis of the screw and center line of the femoral head is between one-half and one screw-diameter; and 3 points, the axis of the screw is located more than one screw-diameter from the center line of the femoral head. $\neq 1$ point, $40-60 \%$ of the threads engage the physis; 2 points, $<40 \%$ or $>60 \%$ of the threads engage the physis.

*Mann-Whitney's $U$ test, IPearson's $X^{2}$ test, §Fisher's exact probability test.

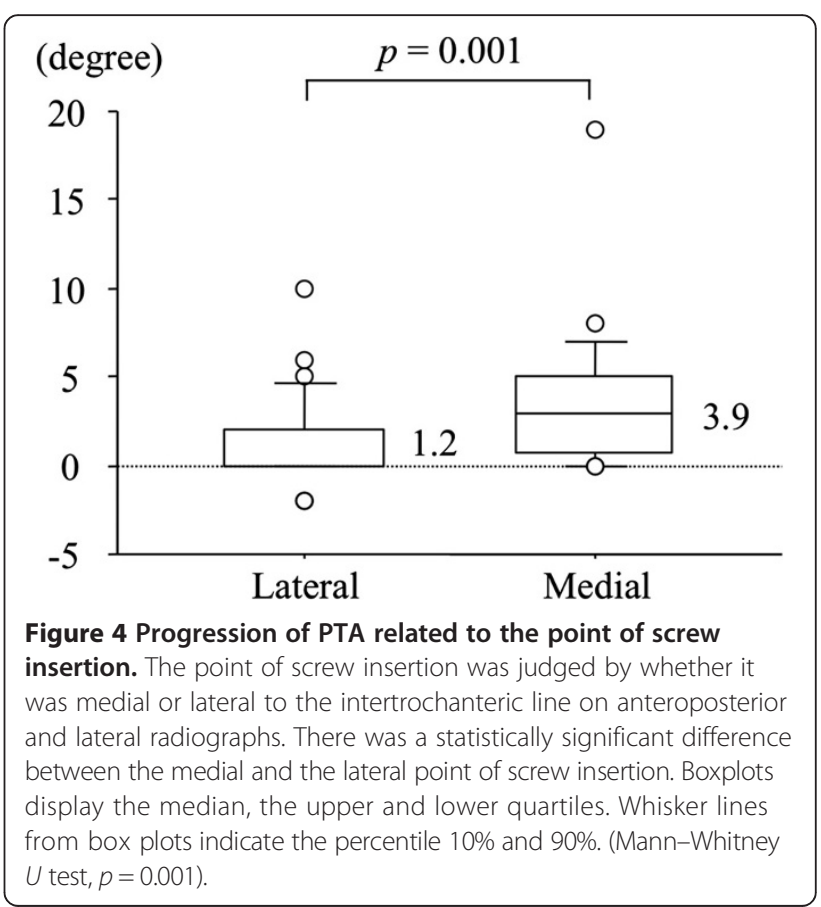


the anterior femoral neck perpendicular to the physis at the center of the femoral head through an anterolateral approach with the patient in the supine position to prevent screw penetration into the joint [17]. According to this method, the point of screw insertion is medial in severe SCFE. Riley et al. reported 26\% of 308 SCFE hips showed screw-related complications and claimed that a lateral insertion of the screw could damage the posterior wall of the femoral neck and posterior superior retinacular vessels, which provide the major blood supply of the femoral head, and the screw could break when it exits the femoral neck before entering the femoral head [27]. In this study, PTA at ISF was expectedly greater in the medial group than in the lateral group with a statistical difference. However, we still hold a warning for the medial insertion because slip progression after ISF would likely happen. It is true that lateral insertion is technically demanding in severe SCFE, but using an image intensifier intra-operatively, the screw positioning can be easily confirmed and such penetration can be avoided [28]. Moreover, three-dimensional computed tomography is helpful for preoperative planning and navigation surgery [29].

Ward et al. reported that mean time to physeal closure was 13 months with single screw fixation and longer with eccentric placement of the screw [26]. In general, the longer time to physeal closure is a likely risk factor for further slippage, as the slip could progress during this period. In this study, time to physeal closure was consistent with Ward's report, but there was no significant difference between the slip-retention group and the slip-progression group or between the lateral and the medial insertion groups. Sanders pointed out that when a screw was inserted into osteopenic bone in the proximal femoral metaphysis, it was likely to loosen and accelerate the slippage of the epiphysis [23] (Figures 2 and 3).

Some biomechanical and clinical studies suggest that double screws rather than a single screw is better, due to increased rotational stability under torsional loading conditions $[22,30,31]$. Other studies have recommended a single screw, and have shown excellent clinical results and a lower complication rate in ISF [17,32]. Single screw fixation is technically easier and safer, and decreases the prevalence of penetration into the joint.

Upasani et al. reported that maximum stability was gained when $40 \%-60 \%$ of the threads engaged the epiphysis using a $16 \mathrm{~mm}$-thread single screw [18]. Carney et al. recommended that five or more threads should engage the epiphysis [24]. In our study, the distribution of the threads was not a prognostic factor.

Patient characteristics such as the growth spurt, endocrinologic disorders, unstable slip, or acute-on-chronic slip were previously reported as risk factors, although they were not found to be significant factors in this study.
There were several limitations to this study. First, because of its retrospective nature, patient characteristics varied, and each operation was performed according to the surgeon's preference and best judgment. A prospective comparative trial is desirable to validate our results. Second, all the measurements were based on simple radiographs, and may have included some measurement error. However, inter-observer and intra-observer measurements were shown statistically to be closely related. Thus, we conclude that radiographic evaluation is still the gold standard for pediatric patients. Further study is needed using computed tomography or magnetic resonance imaging to determine whether these are more reliable or more accurate.

\section{Conclusions}

The incidence of slip progression after ISF in SCFE was $53 \%$ (28 of 53 hips). More than five degrees of progression occurred in 14 hips (26\%). Lateral screw insertion was a favorable prognostic factor in ISF.

\section{Competing interests}

All authors declare that they have no competing interests.

\section{Authors' contributions}

$\mathrm{SH}$ and MK made substantial contributions to conception and design, or acquisition of data, or analysis and interpretation of data and drafted the manuscript. JN involved in drafting the manuscript or revising it critically for important intellectual content. ST and JK participated in the design of the study and performed the statistical analysis. SO and SK conceived of the study, and participated in its design and coordination and helped to draft the manuscript. KT gave final approval of the version to be published. All authors read and approved the final manuscript.

\section{Acknowledgements}

This study was funded in part by Grants-in-Aid for Scientific Research, Japan (Research Project Number: 25870125). We would especially like to thank the study participants who made this study possible.

\section{Author details}

${ }^{1}$ Department of Orthopaedic Surgery, Graduate School of Medicine, Chiba University, 1-8-1 Inohana, Chuo-ku, Chiba City, Chiba 260-8677, Japan. ${ }^{2}$ Chiba Child and Adult Orthopaedic Clinic, 3-24-2 Oyuminominami, Midori-ku, Chiba City, Chiba 266-0007, Japan. ${ }^{3}$ Division of Orthopaedic Surgery, Chiba Children's Hospital, 579-1 Heta-chou, Midori-ku, Chiba City, Chiba 266-0007, Japan.

Received: 29 March 2014 Accepted: 23 September 2014 Published: 26 September 2014

\section{References}

1. Exener GU: Growth and pubertal development in slipped capital femoral epiphysis: a longitudinal study. J Pediatr Orthop 1986, 6:403-409.

2. Hägglund G, Hansson LI, Ordeberg G: Epidemiology of slipped capital femoral epiphysis in southern Sweden. Clin Orthop Relat Res 1984, 191:82-94.

3. Loder RT: The demographics of slipped capital femoral epiphysis: An international multicenter study. Clin Orthop Relat Res 1996, 322:8-27.

4. Wilcox PG, Weiner DS, Leighley B: Maturation factors in slipped capital femoral epiphysis. J Pediatr Orthop 1988, 8:196-200.

5. Alzaharani A, Bali K, Gudena R, Railton P, Ponjevic D, Matyas JR, Powell JN: The innervation of the human acetabular labrum and hip joint: an anatomic study. BMC Musculoskelet Disord. 2014, 15:41.

6. Dodds MK, McCormack D, Mulhall KJ: Femoroacetabular impingement after slipped capital femoral epiphysis: does slip severity predict clinical symptoms? J Pediatr Orthop 2009, 29:535-539. 
7. Kamegaya M, Saisu T, Nakamura J, Murakami R, Segawa Y, Wakou M: Drehmann sign and femoro-acetabular impingement in SCFE. J Pediatr Orthop 2011, 31:853-857

8. Mamisch TC, Kim YJ, Richolt JA, Millis MB, Kordelle J: Femoral morphology due to impingement influences the range of motion in slipped capital femoral epiphysis. Clin Orthop Relat Res 2009, 467:692-698.

9. Hoell S, Sander M, Gosheger G, Ahrens H, Dieckmann R, Hauschild G: The minimal invasive direct anterior approach in combination with large heads in total hip arthroplasty - is dislocation still a major issue? A case control study. BMC Musculoskelet Disord 2014, 15:80.

10. Kawai T, Tanaka C, Kanoe H: Total hip arthroplasty for Crowe IV hip without subtrochanteric shortening osteotomy -a long term follow up study. BMC Musculoskelet Disord 2014, 15:72.

11. Goodman DA, Feighan JE, Smith AD, Latimer B, Buly RL, Cooperman DR: Subclinical slipped capital femoral epiphysis. Relationship to osteoarthrosis of the hip. J Bone Joint Surg Am 1997, 79:1489-1497.

12. Kamegaya M, Saisu T, Ochiai N, Moriya H: Preoperative assessment for intertrochanteric femoral osteotomies in severe chronic slipped capital femoral epiphysis using computed tomography. J Pediatr Orthop B 2005, 14:71-78.

13. Millis MB, Novais EN: In situ fixation for slipped capital femoral epiphysis: perspectives in 2011. J Bone Joint Surg Am 2011, 93(Suppl 2):46-51.

14. Aronson DD, Peterson DA, Miller DV: Slipped capital femoral epiphysis. The case for internal fixation in situ. Clin Orthop Relat Res 1992, 281:115-122.

15. Aronson DD, Loder RT, Breur GJ, Weinstein SL: Slipped capital femoral epiphysis: current concepts. J Am Acad Orthop Surg 2006, 14:666-679.

16. Southwick WO: Osteotomy through the lesser trochanter for slipped capital femoral epiphysis. J Bone Joint Surg Am 1967, 49:807-835.

17. Aronson DD, Carlson WE: Slipped capital femoral epiphysis. A prospective study of fixation with a single screw. J Bone Joint Surg Am 1992, 74:810-819.

18. Upasani V, Kishan S, Oka R, Mahar A, Rohmiller M, Pring M, Wenger D: Biomechanical analysis of single screw fixation for slipped capital femoral epiphysis: are more threads across the physis necessary for stability? J Pediatr Orthop 2006, 26:474-478.

19. Goodwin RC, Mahar AT, Oswald TS, Wenger DR: Screw head impingement after in situ fixation in moderate and severe slipped capital femoral epiphysis. J Pediatr Orthop 2007, 27:319-325.

20. Rao SB, Crawford AH, Burger RR, Roy DR: Open bone peg epiphysiodesis for slipped capital femoral epiphysis. J Pediatr Orthop 1996, 16:37-48.

21. Fleiss JL, Cohen J, Everitt BS: Large-sample standard errors of kappa and weighted kappa. Psychol Bull 1969, 72:323-327.

22. Denton JR: Progression of a slipped capital femoral epiphysis after fixation with a single cannulated screw. A case report. J Bone Joint Surg Am 1993, 75:425-427.

23. Sanders JO, Smith WJ, Stanley EA, Bueche MJ, Karol LA, Chambers HG: Progressive slippage after pinning for slipped capital femoral epiphysis. J Pediatr Orthop 2002, 22:239-243.

24. Carney BT, Birnbaum P, Minter C: Slip progression after in situ single screw fixation for stable slipped capital femoral epiphysis. J Pediatr Orthop 2003, 23:584-589.

25. Morrissy RT, Busch MT: Windshield-wiper loosening: a complication of in situ screw fixation of slipped capital femoral epiphysis. J Pediatr Orthop 1994, 14:549-550.

26. Ward WT, Stefko J, Wood KB, Stanitski CL: Fixation with a single screw for slipped capital femoral epiphysis. J Bone Joint Surg Am 1992, 74:799-809

27. Riley PM, Weiner DS, Gillespie R, Weiner SD: Hazards of internal fixation in the treatment of slipped capital femoral epiphysis. J Bone Joint Surg Am 1990, 72:1500-159.

28. Walters R, Simon SR: Joint destruction: A sequel of unrecognized pin penetration in patients with slipped capital femoral epiphysis. In The Hip: Proceedings of the Eighth Open Scientific Meeting of the Hip Society. Edited by Reilly LH Jr. St. Louis: CV Mosby; 1980:145.

29. Yoram W, Liebergall M, Simanovsky N, Porat S, Moshieff R: Computerized navigation for treatment of slipped femoral capital epiphysis. HSS J 2006, 2:172-175.

30. Kruger DM, Herzenberg JE, Viviano DM, Hak DJ, Goldstein SA: Biomechanical comparison of single- and double-pin fixation for acute slipped capital femoral epiphysis. Clin Orthop Relat Res 1990, 259:277-281.
31. Segal LS, Jacobson JA, Saunders MM: Biomechanical analysis of in situ single versus double screw fixation in a nonreduced slipped capital femoral epiphysis model. J Pediatr Orthop 2006, 26:479-485.

32. Blanco JS, Taylor B, Johnston CE 2nd: Comparison of single pin versus multiple pin fixation in treatment of slipped capital femoral epiphysis. J Pediatr Orthop 1992, 12:384-389.

doi:10.1186/1471-2474-15-317

Cite this article as: Hagiwara et al:: Lateral insertion is a good prognostic factor after in situ fixation in slipped capital femoral epiphysis. BMC Musculoskeletal Disorders 2014 15:317.

\section{Submit your next manuscript to BioMed Central and take full advantage of:}

- Convenient online submission

- Thorough peer review

- No space constraints or color figure charges

- Immediate publication on acceptance

- Inclusion in PubMed, CAS, Scopus and Google Scholar

- Research which is freely available for redistribution 